DIW BERLIN

Discussion

Papers

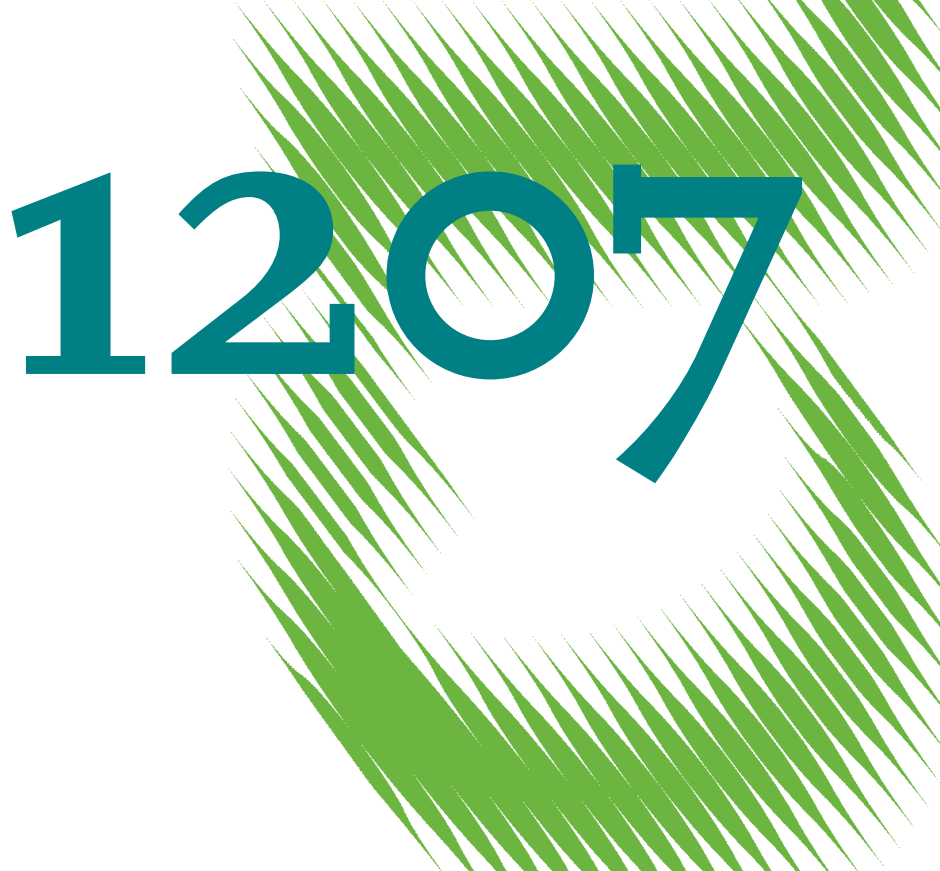

Forecasting the Prices and Rents for Flats in Large German Cities 
Opinions expressed in this paper are those of the author(s) and do not necessarily reflect views of the institute.

IMPRESSUM

(C) DIW Berlin, 2012

DIW Berlin

German Institute for Economic Research

Mohrenstr. 58

10117 Berlin

Tel. $+49(30) 89789-0$

Fax +49 (30) $89789-200$

http://www.diw.de

ISSN print edition $1433-0210$

ISSN electronic edition 1619-4535

Papers can be downloaded free of charge from the DIW Berlin website:

http://www.diw.de/discussionpapers

Discussion Papers of DIW Berlin are indexed in RePEc and SSRN:

http://ideas.repec.org/s/diw/diwwpp.html

http://www.ssrn.com/link/DIW-Berlin-German-Inst-Econ-Res.html 


\title{
Forecasting the prices and rents for flats in large German cities
}

\author{
Konstantin A. Kholodilin* Andreas Mense ${ }^{\S}$
}

Corrected version

December 11, 2012

\begin{abstract}
In this paper, we make multi-step forecasts of the monthly growth rates of the prices and rents for flats in the 25 largest German cities. Given the small time dimension, the forecasts are done in a panel-data format. In addition, we use panel models that account for spatial dependence between the growth rates of housing prices and rents. Using a quasi out-of-sample forecasting exercise, we find that both pooling and accounting for spatial effects helps to substantially improve the forecast performance compared to the benchmark models estimated for each of the cities separately. In addition, a true out-of-sample forecasting of the growth rates of flats' prices and rents for the next 12 months is done. It shows that in most cities both prices and rents for flats are going to increase, with prices growing stronger than the rents.
\end{abstract}

Keywords: Housing prices; housing rents; forecasting; dynamic panel model; spatial autocorrelation; German cities.

JEL classification: C21; C23; C53.

\footnotetext{
*DIW Berlin, Mohrenstraße 58, 10117 Berlin, Germany, e-mail: kkholodilin@diw.de

$\S$ Friedrich-Alexander-Universität Erlangen-Nürnberg, Kochstraße 4, 91054 Erlangen, Germany, e-mail: Andreas.Mense@wiwi.phil.uni-erlangen.de
} 


\section{Contents}

1 Introduction 1

2 Internet-based indices $\quad 2$

$\begin{array}{llr}3 & \text { Forecasting models } & 6\end{array}$

4 Estimation results $\quad 10$

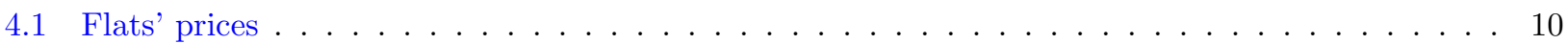

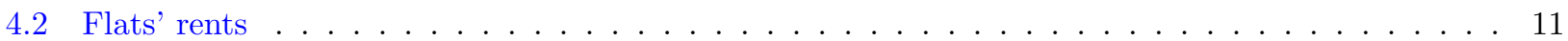

$\begin{array}{llr}5 & \text { Forecast accuracy } & 11\end{array}$

6 Conclusion $\quad 14$

$\begin{array}{lr}\text { References } & 15\end{array}$

$\begin{array}{ll}\text { Appendix } & 17\end{array}$ 


\section{List of Tables}

1 Structural characteristics of a typical flat $\ldots \ldots \ldots \ldots \ldots \ldots \ldots \ldots$

2 Summary of estimation results of hedonic regressions $\ldots \ldots \ldots \ldots \ldots \ldots$

3 Descriptive statistics of prices and rents for flats, $\%, 2007: 1-2012: 9 \ldots \ldots \ldots$

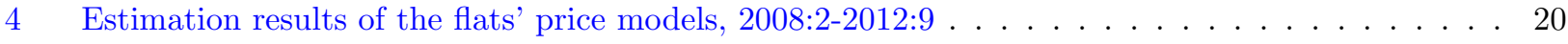

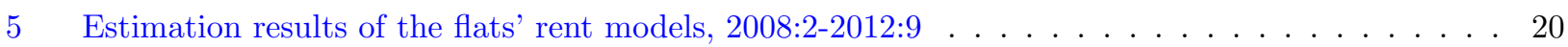

6 Quasi out-of-sample forecast accuracy of flats' price models (RMSFE), 2010:1-2012:9 _ . . . . 21

7 Quasi out-of-sample forecast accuracy of flats' rent models (RMSFE), 2010:1-2012:9 _ . . . . . 21

8 Predicted average year-on-year growth rates of prices and rents for flats, \%, 2012:10-2013:10 . . . 22

\section{List of Figures}

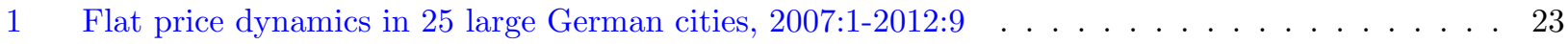

2 Flat rent dynamics in 25 large German cities, 2007:1-2012:9 . . . . . . . . . . . . . . 24

3 Price-to-rent ratios in 25 large German cities, 2007:1-2012:9 (continued) . . . . . . . . . . 25

4 Year-on-year growth rates of flat prices in 25 large German cities: actual and predicted, 2008:2-

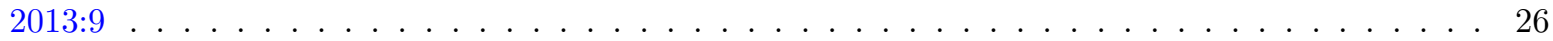

5 Year-on-year growth rates of flat rents in 25 large German cities: actual and predicted, 2008:2-2013:9 27 


\section{Introduction}

The role of the housing market in the everyday life of society is difficult to overestimate. Home rents and prices directly affect the standard of living of every person. It is well known now that bubbles on real-estate markets are likely to trigger financial crises, which in turn spill over to the real economy. For these reasons alone, it is very important to estimate and forecast home rents and prices. Both problems are especially acute in Germany.

The first problem is a lack of data on real-estate prices in Germany and its regions. Probably due to the fact that housing prices in Germany had been stagnating for decades, very little attention was paid to constructing long time series of home price indices at the regional level. In recent years, the situation started to change, see Kholodilin and Mense (2012).

The second problem is a lack of studies on forecasting housing prices in Germany. To the best of our knowledge, there exists only one paper — an de Meulen et al. (2011) — that forecasts German real estate prices for four different market segments (new and existing houses and apartments) using ARDL and VAR as well as forecast combination approaches. Their study is based on monthly data provided by Immobilienscout24 dating back to 2007. The benchmark is a simple AR model. The authors find that ARDL and VAR forecasts singlehandedly can hardly improve upon the accuracy of AR forecasts, but find some substantial improvements when weighing the forecasts with the forecast errors of previous periods, especially for the existing houses segment. Clustering, see Aiolfi and Timmermann (2006), proves beneficial in a similar fashion. However, the authors consider only the German market as a whole and do not take into account spatial dependencies.

In this paper, we are trying to solve both problems. First, we construct flats' price and rent indices for 25 large German cities. Second, we suggest a model to simultaneously forecast prices and rents for flats in these cities.

The rent/price estimates are based on data of the largest German Internet site Immobilienscout24 offering housing for sale and for rent. We collect the data on a monthly basis beginning in June 2010. Hence, the sample is relatively short. We circumvent this problem by pooling the growth rates of housing rents/prices into a panel and correspondingly utilizing panel data models for forecasting. The advantages of such a pooling approach for forecasting have been widely demonstrated in a series of articles for diverse data sets such as Baltagi and Griffin (1997) and Brücker and Siliverstovs (2006), among others. 
In addition to pooling, accounting for spatial interdependence between regions may prove beneficial for the purposes of forecasting. Spatial dependence implies that due to spillover effects (e.g., commuter labor and trade flows) neighboring regions may have a similar economic performance and hence location matters. However, the number of studies that illustrate the usefulness of accounting for (possible) spatial dependence effects across cross sections in the forecasting exercise is still limited. For example, Elhorst (2005), Baltagi and Li (2006), and Longhi and Nijkamp (2007), Kholodilin et al. (2008), and Girardin and Kholodilin (2011) demonstrate the forecast superiority of models accounting for spatial dependence across regions using data on demand for cigarettes from states of the USA, demand for liquor in the American states, and German regional labor markets, GDP of German federal states (Bundesländer), and GDP of Chinese provinces, respectively.

The paper has the following structure. Section 2 outlines the construction of our Internet-based flats' price/rent indices for large German cities. Section 3 introduces the forecasting models. In section 4, the estimation results are reported, whereas section 5 compares the quasi out-of-sample forecast accuracy of alternative models and examines the true out-of-sample forecasts. Finally, section 6 concludes.

\section{Internet-based indices}

This study uses data contained in Internet ads on flats offered for sale and for rent in Germany. The data were provided to authors by the most popular German real-estate advertisements website Immobilienscout24.de as a part of its initiative called "Transparenzoffensive", whose objective is to improve the transparency in the German real-estate market. The data are monthly and start in January 2007 and go through September 2012.

There are, of course, other sites, where such ads are placed. However, due to its large market share, Immobilienscout24 is representative enough. For example, at the end of January 2012 the ranking of the different websites that publish real-estate announcements, according to the number of ads offering flats and houses for rent and sale, was as follows: Immobilienscout24.de (224,400), Quoka.de (155,600), Immowelt.de (142,000), Immonet.de (139,100), Immobilien.de (37,600), and Kalaydo.de (28,600). It should be noticed that about $10 \%$ of the Quoka.de ads are from its partner site Immobilienscout24. Given these figures, Immobilienscout24 has a market share of approximately $31 \%$.

Our sample includes 25 large German cities. They were selected based on their population size as well as 
the number of ads, see Table 3. This is done in order to guarantee the representativeness of data. Too few ads may lead to an overly volatile price or rent index. Table 3 shows that the population of the selected cities attains almost 20 million persons, which is about $25 \%$ of the total population of Germany. Over the period 2007:1-2012:9, the number of usable ads of flats for sale is about 2,9 millions, whereas the number of ads of flats for rent is over 5,7 millions. This reflects the dominance of tenant-occupied over owner-occupied housing in Germany. The correlation between the population and the number of ads of flats for sale and for rent is 0.93 and 0.62 , respectively. The low correlation in the latter case is due to the overproportionate number of ads in Leipzig, where landlords are having problems in renting out their flats. When Leipzig is excluded, the correlation jumps to 0.88 . Overall, the high correlations imply that our data are geographically representative.

Given that the prices and rents contained in the advertisements vary widely depending on structural and locational characteristics of flats, we use hedonic regression in order to obtain quality-adjusted rents/prices. According to this approach, the square-meter price/rent of an advertized flat $i$ can be represented as:

$$
P_{i}=\alpha+\sum_{j=1}^{J} \beta_{j} S_{j i}+\sum_{k=1}^{K} \gamma_{k} L_{k i}+\sum_{t=1}^{T} \delta_{t} D_{t i}+\epsilon_{i}
$$

where $S$ are the structural characteristics, such as number of rooms, area in $m^{2}$, type of flat (ordinary flat, studio, loft, maisonette, etc.); $L$ are the locational characteristics, which are captured by the ZIP codes; $D$ are time dummies reflecting the change in prices/rents over time. Parameters to be estimated, $\alpha, \beta, \gamma$, and $\delta$, should reflect the value attached to each of these characteristics by the landlord selling or renting out his flat. Finally, $\epsilon_{i}$ reflects the unexplained part of price/rent variation. Ideally, it is identically and independently distributed white noise.

A summary of estimation results of hedonic regressions is reported in Table 2. To save space we report only the parameter estimates on the number of rooms, area, type "ordinary flat" (in German "Etagenwohnung"), lowest and highest ZIP code coefficients. In addition, the table reports the sample size $N$, number of regressors $K$, and $R^{2}$. The fit is higher for the models of prices than for those of rents. Moreover, it is higher for those cities with a larger sample size. It is the highest for flats for sale in Berlin $\left(R^{2}=0.671\right)$ and flats for rent in Bremen $\left(R^{2}=0.537\right)$.

Using the estimated parameters we computed quality-adjusted prices and rents for a typical flat, which is a 
flat with 3 rooms, an area of $75 \mathrm{~m}^{2}$, and a type "Etagenwohnung". Notice that the structural characteristics vary quite widely both across cities and across markets of flats for sale and flats for rent, see Table 1. However, to make results comparable, we use the median structural characteristics of flat for sale to calculate both prices and rents. In addition, based on variability of locational characteristics, as measured by ZIP code dummies, we compute for each city the price/rent in the cheapest location (lowest coefficient of the ZIP code dummy), median location (median of coefficients of ZIP code dummies), and the most expensive location (highest ZIP code dummy coefficient). The hedonic price/rent in the median location is taken as a representative rent/price for the whole city.

The quality-adjusted flats' price indices are shown in Figure 1, while quality-adjusted flats' rent indices are depicted in Figure 2. The red line is the trajectory of the average flat prices/rents in 25 cities. The dark blue line shows the quality-adjusted price/rent levels in a corresponding city. The blue areas represent the price continuum between the cheapest and the most expensive ZIP code locations.

It can be seen in Figure 1 that in majority of the cities the flat prices have been increasing. This is also reflected in the upward sloping average price index (red line). It is worth noticing that till the end of 2009 the average price for flats in 25 cities was stagnating (average year-on-year growth rate between January 2008 and January 2010 was close to zero). However, in the course of 2010 the housing market started to accelerate (average year-on-year growth rate between February and September 2010 went up to 1.5\%) and in October of that year the price for flats took off. The average year-on-year growth rate since then attained 5.4\%. The same tendency can be traced in most of the cities under consideration. It is especially pronounced in Berlin, Dresden, and München. In Hamburg the price growth acceleration started several months earlier. There are about 10 cities, where the flat prices remain stagnant or even decline, for example, in Dortmund, Duisburg, and Wuppertal. Strikingly, all of these cities are located in the State of North-Rhine-Westphalia and only two of them do not belong to the depressive Ruhrgebiet (Ruhr-Rhine area).

As seen in Figure 2, the rent growth has been much more graduate. Some acceleration started also in October 2010: between January 2008 and September 2010, average year-on-year growth rate of rent was 1.4\%, while between October 2010 and September 2012, it went up to 2.4\%. None of the 25 largest German cities observed a decline in the rent level. In some cities, such as Duisburg, Essen, and Wuppertal, rents remained 
roughly constant.

Table 3 reports some descriptive statistics on prices and rents for flats. In 11 cities -Berlin, Düsseldorf, Frankfurt am Main, Hamburg, Köln, Mannheim, München, Nürnberg, Stuttgart, and Wiesbaden- the prices are substantially higher than the average of the 25 cities. The city with the highest flats' prices is München, where the price level is more than double of the cities' average. In Berlin, prices were close to the average until the end of 2009-2010, but since then diverged substantially from it. In fact, Berlin experienced the highest growth of prices for flats in the sample: since January 2007 the price went up by almost $73 \%$, which corresponds to an annualized monthly growth rate of $0.8 \%$. This by far exceeds the growth in those two cities with the strongest price increases, Hamburg and München, where the annualized monthly growth turned out to be $0.6 \%$ and $0.5 \%$, respectively. To some extent, such a strong price growth in Berlin can be explained by the "low basis effect", for originally it had relatively low flat prices. The ratio between the quality-adjusted price in the most expensive ZIP code area to that in the cheapest ZIP code area can also provide an interesting insight in the spatial heterogeneity of the housing market. On average, the ratio is about 4, meaning that in the most expensive neighborhood the square-meter price of a comparable flat is 4 times larger than in the cheapest neighborhood. The ratio is highest in Hamburg, where it exceeds 11. It is also very high in Duisburg, Köln, and Nürnberg. In Berlin, it is only somewhat above the average.

The same 11 cities with flat prices above average are also those for which the rents exceed the average of the 25 cities. However, in Berlin, the quality-adjusted rent, 7.3 euros in September 2012, is still larger than the average, 7.2 euros, by a very small margin. In fact, as Figure 2 shows, rents in Berlin caught up the average cities' rent only by the end of 2011. The highest rents are demanded in München (12.3 euros) and Hamburg (10.9 euros). Judging by the ratio of quality-adjusted rent in the most expensive ZIP code area to that in the cheapest ZIP code area, the market of flats for rent is much more homogeneous spatially than the market of flats for sale. Moreover, in the case of the rent market, the differences between cities in terms of this ratio are minor.

Finally, Table 3 reports the flat price-to-rent ratio in September 2012, which is computed as $\frac{P}{12 \times R}$, where $P$ is the price per $m^{2}$ and $R$ is the rent per $m^{2}$. It means that in 19 years a tenant pays out to the landlord the complete value of the flat he rents. On average in 25 cities, the ratio is about 19 . It is the highest in Berlin 
(25.6), München (25.4), and Hamburg (24.6). The dynamics of the ratio can be seen in Figure 3. Notice that due to a much stronger price than rent growth, the ratio in these cities that had been almost constant at 20 previously, went up strongly in the middle of 2011. A similar tendency can be observed for Frankfurt-am-Main, Köln, and Wiesbaden.

The significant increases in the growth rates of home prices and of the price-to-rent ratios that we observe in the last few years in the most attractive German cities lead to the question, as to what extent these tendencies can be explained by fundamental factors. Although this paper cannot provide a thorough answer, the sharp increases in the price-to-rent ratios suggest that the expectation of further price increases rather than increases in rent payments are a driving force behind this development. An obvious explanation would be the loose stance of the European Central Bank since 2008, which is reflected in the increase in money supply and decreasing real-estate bank rates coupled with general uncertainty in the Euro Area that foster a flight towards "real" values. However, this policy change served only as a trigger of a home price surge at a backgroud of a widening housing shortage in the cities in question. The gap between demand for housing and supply of it is resulting from a strong influx of migrants from other regions, that some large cities have been experiencing in the recent years, and stagnation in the construction sector during the last decades. Of course, the gap should also exert an upward pressure on rents, thus reducing a bit the price-to-rent ratio, but German law imposes quite strict upper restrictions on them, which makes it more difficult to raise the home rents. This can be also seen in their smoother dynamics. At the same time, there are virtually no restrictions on flats' price increases.

\section{$3 \quad$ Forecasting models}

In this section, we describe the econometric models that we use for forecasting the growth rates of flats' prices and rents in 25 large German cities.

We examine a wide range of dynamic panel data (DPD) models starting with individual autoregressive (AR) models, which can be considered as a particular case of DPD models with unrestricted parameters, through fixed-effects models, which impose homogeneity restrictions on the slope parameters, to pooled models, which impose homogeneity restrictions on both intercept and slope parameters. In addition to standard fixed-effects and pooled models, we also consider fixed-effects and pooled models that account for spatial dependence. Two 
naïve models are also considered: 1) a model where the present month's value is used as a forecast for the next month, and 2) a model, where the forecast is the average of the growth rates in the past.

As a benchmark model, with which all other models will be compared, we use a linear individual AR(1) model $\left(I_{O L S}\right)$ and estimate it for each city separately:

$$
y_{i t}=\alpha_{i}+\beta_{i} y_{i t-1}+\varepsilon_{i t} \quad \varepsilon_{i t} \sim \text { N.I.D. }\left(0, \sigma_{i}^{2}\right)
$$

where $y_{i t}$ is the year-on-year monthly growth rate of flats' prices/rents in the $i$-th city; $t$ is the time index $t=1, \ldots, T$. In total, since our sample covers the period between January 2007 and September 2012, we have $T=57$, for the first 12 observations are lost due to differencing. The 12 th order differencing, albeit it leads to a loss of some observations, has two important advantages: 1) it smooths the price/rent time series, which, despite hedonic quality adjustment remain relatively volatile; and 2) removes the possible seasonality from the data.

In addition, given the short time dimension of our data, it should be noted that the OLS estimator of the parameters of individual $\mathrm{AR}(1)$ models is biased due to insufficient degrees of freedom as pointed out in Ramanathan (1995).

The next model we consider is the pooled panel, $P_{O L S}$, model:

$$
y_{i t}=\alpha+\beta y_{i t-1}+\varepsilon_{i t} \quad \varepsilon_{i t} \sim \text { N.I.D. }\left(0, \sigma^{2}\right)
$$

which imposes the homogeneity restriction on both intercept and slope coefficients across all cities.

An alternative model is the fixed-effects, $F_{O L S}$, model that allows for city-specific intercepts:

$$
y_{i t}=\alpha_{i}+\beta y_{i t-1}+\varepsilon_{i t} \quad \varepsilon_{i t} \sim \text { N.I.D. }\left(0, \sigma^{2}\right)
$$

The fixed-effects model represents an intermediate case between the individual, $I_{O L S}$, and pooled panel, $P_{O L S}$, models. It is not as restrictive as the pooled model, which assumes equal average price trends in all cities, and yet allows to take advantage of the panel dimension. From the economic point of view, fixed effects 
capture differences in price/rent trends between cities related to their heterogeneous economic and demographic structure.

Moreover, we consider the following two types of models that account for spatial correlation that might exist between the cities: the spatial-lag and spatial-error models. One may expect to find the dynamic (stagnating) cities being the neighbors of other dynamic (stagnating) cities due to cross-city spillovers (commuter labor and regionally connected housing markets).

The spatial dependence is accounted for using an $N \times N$ matrix of spatial weights $W$ which is based on the distance between the cities. We constructed a distance-decay weights matrix with a typical element, $w_{i j}$, defined as:

$$
w_{i j}=\frac{1}{d_{i j}^{2}}
$$

where $d_{i j}$ is the great circle distance between the city $i$ and city $j$.

Moreover, all the elements on the main diagonal of matrix $W$ are equal to zero. The constructed weights matrix is normalized such that all the elements in each row sum up to one. Various distance cutoff values, including third decile, median, and maximum distance between all cities, were tried. Finally, we chose the maximum distance, or no cutoff, since it provides the best forecast accuracy. It should be noticed that the forecast accuracy does not change noticeably depending on cutoff value.

First, we model the spatial dependence by means of spatial lags of the dependent variable. Typically, it is assumed that the spatial lag model (SLM) accounts for spillover effects, which are exerted by a city on its neighbors. Such effects result, for example, from a connection due commuter labor or the general perception of a region, i.e. the Rhine-Ruhr area. We examine both pooled and fixed-effects versions of this model. The pooled spatial lag model $\left(P_{M L E}^{S L M}\right)$ can be written as follows:

$$
y_{i t}=\alpha+\beta y_{i t-1}+\rho \sum_{j=1}^{N} w_{i j} y_{j t}+\varepsilon_{i t} \quad \varepsilon_{i t} \sim \text { N.I.D. }\left(0, \sigma^{2}\right)
$$


The fixed-effects spatial lag model $\left(F_{M L E}^{S L M}\right)$ is:

$$
y_{i t}=\alpha_{i}+\beta y_{i t-1}+\rho \sum_{j=1}^{N} w_{i j} y_{j t}+\varepsilon_{i t} \quad \varepsilon_{i t} \sim N . I . D .\left(0, \sigma^{2}\right)
$$

where $\rho$ is the spatial autoregressive parameter and $N$ is the number of provinces.

The second type of models addresses spatial correlation through a spatial autoregressive error structure, as suggested by Elhorst (2005). Unlike the SLM, the spatial error model (SEM) is thought to reflect so-called "nuisance" spatial effects, which result, for instance, because the administrative borders do not coincide with the boundaries of the markets. Again, we distinguish between pooled and fixed-effects models. Due to their specific nature, those models are estimated by the Maximum Likelihood method (MLE). The pooled spatial error model $\left(P_{M L E}^{S E M}\right)$ has the following form:

$$
y_{i t}=\alpha+\beta y_{i t-1}+u_{i t} \quad u_{i t}=\lambda \sum_{j=1}^{N} w_{i j} u_{j t}+\varepsilon_{i t} \quad \varepsilon_{i t} \sim N . I . D .\left(0, \sigma^{2}\right)
$$

The fixed-effects spatial error model $\left(F_{M L E}^{S E M}\right)$ can be expressed as:

$$
y_{i t}=\alpha_{i}+\beta y_{i t-1}+u_{i t} \quad u_{i t}=\lambda \sum_{j=1}^{N} w_{i j} u_{j t}+\varepsilon_{i t} \quad \varepsilon_{i t} \sim \text { N.I.D. }\left(0, \sigma^{2}\right)
$$

where $\lambda$ is the coefficient of spatial error autoregression.

We estimate $I_{O L S}, P_{O L S}$, and $F_{O L S}$ using the OLS method. It is known from the literature that in the context of dynamic panel data models the OLS estimator is subject to a simultaneous equation bias. In order to address this problem it is suggested to use the GMM estimator of Arellano and Bond (1991) to estimate the fixed-effects model without spatial autoregressive lags. Although from the theoretical perspective, the GMM estimators should be preferred to the OLS estimators when applied to dynamic panels with small time dimension, in what follows we use the OLS estimators ${ }^{1}$, since in the forecasting context a biased but stable estimator may still deliver a more accurate forecasting performance than an unbiased but unstable one.

The remaining dynamic panel models accounting for spatial effects were estimated using the Maximum

\footnotetext{
${ }^{1}$ The computations were performed using the DPD package for Ox, see Doornik et al. (2006).
} 
Likelihood method as implemented in the Ox codes written by Konstantin A. Kholodilin² .

\section{Estimation results}

\subsection{Flats' prices}

The estimates of the temporal and spatial autoregressive coefficients of all models of flats' prices are presented in Table 4.

First, we report a summary of the estimates of intercept, $\widehat{\alpha_{i}}$, and the temporal autoregressive coefficient, $\widehat{\beta}_{i}$, obtained for an autoregressive model estimated for each province separately and reported in columns (1) through (2) of Table 4. Using the estimated coefficients we computed the conditional means $\left(\frac{\alpha_{i}}{1-\beta_{i}}\right)$ of sale prices for each of the 25 cities. It reflects the mean expected monthly growth rate of price for flats. The average conditional mean is 6.5. Thus, on average the prices for flats in 25 German cities within the last five years have been increasing at a year-on-year growth rate of $6.5 \%$. Indeed, in 16 cities the conditional mean exceeds 0 . The fit of the individual autoregressive models varies considerably, with $R^{2}$ 's between 0.259 and 0.934 .

The columns (3) and (4) of Table 4 contain the estimation results obtained for the pooled model (equation (3)) and for the fixed-effects model (equation (4)) using OLS. All the intercept estimates are positive and significant. The estimates of temporal autoregressive parameters for these models are significant and positive. As a result, the conditional mean of the pooled model is similar to the average conditional mean of individual autoregressive models. Given the large heterogeneity of the growth rates of prices, the pooled model can hardly be a good option for the forecasting exercise, since it imposes too much homogeneity. The goodness-of-fit of the panel models without spatial effects is very close to that of the median of individual autoregressive models: in case of the pooled model, $R^{2}=0.820$, while the determination coefficient of the fixed-effects model is $R^{2}=0.637$.

The columns (5) through (8) of Table 4 report the parameter estimates of the panel models accounting for spatial dependence. Again, the estimates of temporal autoregressive coefficients are positive and significant. The estimated spatial autoregressive coefficients are positive and significant. The $R^{2}$ 's of the spatial lag models are again in the same range as those of the models without spatial effects, whereas the spatial error models perform somewhat worse.

\footnotetext{
${ }^{2}$ The codes are available upon request. For details about the Ox programming language see Doornik and Ooms (2006).
} 


\subsection{Flats' rents}

The estimation results of the models of flats' rents are reported in Table 5. Here, the picture is considerably brighter especially for the spatial effects models.

The OLS estimates of the simple AR(1) models are closer together and almost always positive for both the intercept term and the autoregressive coefficient. Unlike the prices for flats, where about $40 \%$ of the cities displayed negative conditional mean growth rates, only in 1 city the rents for flats have been decreasing. The average conditional mean year-on-year growth rate of rents among the 25 cities is $1.8 \%$. The $R^{2}$ is varying between 0.370 and 0.926 .

The pooled and fixed-effects models produce autoregressive coefficients that are significant and quite close to each other. The $R^{2}$ ranges between 0.579 and 0.737 , which is similar to those from the estimations for flats' prices. The spatial dependence coefficients of the spatial-lag and spatial-error models ( $\rho$ and $\lambda$, respectively) estimated for rents of prices are similar in magnitude and often statistically significant flats.

To summarize, on the basis of our estimation results we conclude the following. First, in most cases, the temporal autoregression is statistically significant and thus past prices and rents appear to play an important role in explaining their future values. Second, the spatial dependence is statistically significant both for the market of flats for sale and for that of flats for rent. This implies that there is a relatively high degree of dependence between the housing markets in the neighboring cities. This might be of importance when some regions boom economically, which also drives up prices in the nearby cities. Third, the estimates for autoregressive coefficients appear to be relatively stable for all panel models and both markets. They range from 0.713 to 0.907 and are all statistically significant.

\section{$5 \quad$ Forecast accuracy}

For each model we forecast the $h$-month growth rates of prices/rents for flats, $\Delta^{h} y_{i, t+h}=y_{i, t+h}-y_{i t}$, where $h=1,2, \ldots, 12$ for all 25 cities. The forecasting period is 2010:1-2012:9. The forecasts are made in a recursive manner. First, the models are estimated over the period 2008:2-2009:12. Next, forecasts are made for 2010:1, 2010:2, ., 2011:1. Second, the estimation period is extended to the period 2008:2-2010:1 and the forecasts for 2010:2, 2010:3, $\ldots, 2011: 2$ are made. This procedure gives us $(33-h+1) \times N$ quasi out-of-sample forecasts for 
the $h$-month growth rate. Thus, for $h=1$ we have 825 forecasts, while for $h=12$ we obtain 550 forecasts.

For all models, except for the spatial-lag models, the forecasts are made in a standard way. The forecasts based on the spatial-lag models are conducted using a two-step procedure. In order to illustrate this procedure, it is worthwhile re-writing the spatial-lag models (6) and (7) in the following matrix form for the pooled model:

$$
\mathbf{y}=\alpha \boldsymbol{\imath}_{N T}+\beta \mathbf{y}_{-1}+\rho \mathbf{W} \mathbf{y}+\varepsilon
$$

and for the fixed-effects model:

$$
\mathbf{y}=\left(\boldsymbol{\imath}_{T} \otimes \mathbf{I}_{N}\right) \boldsymbol{\alpha}+\beta \mathbf{y}_{-\mathbf{1}}+\rho \mathbf{W} \mathbf{y}+\varepsilon
$$

where $\mathbf{y}$ is a $N T \times 1$ vector of the $y_{i t}$ stacked by month and city such that the first $N$ observations refer to the first year, etc. Correspondingly, $\mathbf{y}_{-\mathbf{1}}$ is a $N T \times 1$ vector of the $y_{i, t-1}$ stacked by year and province. $\mathbf{I}_{N}, \mathbf{I}_{T}$, and $\mathbf{I}_{N T}$ are the unit matrices with dimensions $N \times N, T \times T$, and $N T \times N T$, respectively. The $N T \times N T$ matrix $\mathbf{W}=\mathbf{I}_{T} \otimes W$ is the block-diagonal matrix with the $N \times N$ matrix $W$ of spatial weights on its main diagonal, where $\otimes$ is the Kronecker product. $\boldsymbol{\imath}_{N T}$ and $\boldsymbol{\imath}_{T}$ are the $N T$ and $T$ unit vectors, respectively, such that $\alpha$ and $\boldsymbol{\alpha}$ are correspondingly a common intercept and a $N \times 1$ vector of cross-section specific intercepts in the pooled and the fixed-effects spatial-lag models.

Models (10) and (11) can be re-written in the following reduced form:

$$
\begin{aligned}
&\left(\mathbf{I}_{\mathbf{N T}}-\rho \mathbf{W}\right) \mathbf{y}=\alpha \boldsymbol{\imath}_{N T}+\beta \mathbf{y}_{-1}+\varepsilon \\
& \mathbf{y}=\left(\mathbf{I}_{\mathbf{N T}}-\rho \mathbf{W}\right)^{-1}\left[\alpha \boldsymbol{\imath}_{N T}+\beta \mathbf{y}_{-1}\right]+\left(\mathbf{I}_{\mathbf{N T}}-\rho \mathbf{W}\right)^{-1} \varepsilon \\
&\left(\mathbf{I}_{\mathbf{N T}}-\rho \mathbf{W}\right) \mathbf{y}=\left(\boldsymbol{\imath}_{T} \otimes \mathbf{I}_{N}\right) \boldsymbol{\alpha}+\beta \mathbf{y}_{-\mathbf{1}}+\boldsymbol{\varepsilon} \\
& \mathbf{y}=\left(\mathbf{I}_{\mathbf{N T}}-\rho \mathbf{W}\right)^{-1}\left[\left(\boldsymbol{\imath}_{T} \otimes \mathbf{I}_{N}\right) \boldsymbol{\alpha}+\beta \mathbf{y}_{-\mathbf{1}}\right]+\left(\mathbf{I}_{\mathbf{N T}}-\rho \mathbf{W}\right)^{-1} \boldsymbol{\varepsilon}
\end{aligned}
$$

where only the past values of $\mathbf{y}$ appear on the right-hand side of the equations.

The multi-step ahead forecasts from the spatial-lag models can now be obtained as follows: First, we estimate the parameters of the models (10) and (11), as outlined above. Secondly, we use the reduced form equations 
(12) and (13) for the models with identical spatial dependence in order to generate the forecasts.

The accuracy of forecasting the flats' prices is reported in Table 6, whereas the forecasting performance of the flat rents models is shown in Table 7. The forecasting performance is measured by the root mean square forecast error (RMSFE) calculated for all months and over all cities for each forecasting horizon, $h=1,2, \ldots, 12$. Each table consists of two panels: The upper panel reports RMSFE, while the lower panel represents the relative RMSFE, that is, RMSFE of each model divided by the corresponding RMSFE of the benchmark (individual autoregressive) model.

The naïve model 1 which uses the previous period value as a forecast astonishingly produces very good forecast accuracy, especially at lower forecast horizons. The forecast accuracy of the naïve model 2, whose forecasts are just the averages of the growth rates in the past, is very poor. This probably has to do with a drastic change in the price and rent trends that we observed above. In the price forecasting exercise, the individual autoregressive models, $I_{O L S}$, are slightly better than Naïve model 1 at the first 5 horizons, but then turn out to be worse. In the rent forecasting case, individual autoregressive models are always worse than Naïve model 1.

For price forecasting, the individual AR model is more accurate than all the panel models without spatial effects and the SEM models. However, they are beaten by the spatial lag models at all horizons and, in particular, by the fixed-effects SLM, $F E_{M L E}^{S L M}$. The latter model is also more accurate than the benchmark Naïve model 1 and produces the forecast accuracy gains between 3 and $7 \%$. The gains are especially large at horizons between 3 and 5 .

In case of forecasting the rents, the Naïve model 1 turns out to be difficult to beat. Again, the best alternative is $F E_{M L E}^{S L M}$, which brings forecast accuracy gains between 1 and $5 \%$ at horizons exceeding $h=8$.

Thus, in line with our expectations, the application of panel models accounting for spatial effects results in a higher forecast accuracy compared to the corresponding non-spatial models. Pooling, fixed effects, and accounting for spatial dependency contribute to the improvement in forecast accuracy.

It would be also interesting to see not only the quasi out-of-sample forecasts of prices and rents for the past periods, but also to really predict them into the future. Therefore, we estimated the models for the whole period, for which the data are available, that is, 2008:2-2012:9, and made a true out-of-sample forecasts. The 
forecasts of flats' prices for the period 2012:9-2013:9 are depicted in Figure 4, whereas the forecasts of flats' rents are shown in Figure 5. The forecasts are made using the fixed-effects spatial-lag model, $F E_{M L E}^{S L M}$, given that this is the best model in terms of forecast accuracy.

Over 2012:10-2013:10, the prices for flats are predicted to increase in 19 cities, see column (2) of Table 8. For five cities — Berlin, Augsburg, Hamburg, München, and Nürnberg — we predict a relatively strong year-on-year monthly flat price increase exceeding 10\%. Interestingly, Dresden's flat prices picked up considerably in 2011 and are expected to increase over the forecast horizon by a year-on-year growth rate close to $10 \%$. This is in contrast to Leipzig, the second city from the former GDR in the sample, where the flats' prices are expected to grow rather slowly in the near future. On the other hand, our forecasts suggest that prices will be relatively constant in the cities of the Ruhrgebiet during the next year. Here, Essen, Bochum, and Krefeld perform especially bad, whereas we expect a slight improvement for Gelsenkirchen, Duisburg, and Mönchengladbach. In Wiesbaden, prices increased considerably during the first months of 2012 and are predicted to do so in the near future as well.

The rents for flats are expected to go up in 24 out of 25 cities. On average, the prices for flats should grow twice as fast as the rents. In the Ruhrgebiet cities - e.g., Bochum, Dortmund, Duisburg, and Essen- just the opposite is expected: here, the prices will decline, whereas the rents will either stagnate or slowly grow. The largest absolute differences between the year-on-year growth rates of prices and those of rents are to be observed in Augsburg (9.5 percentage points), München (9.4), and Berlin (9.3). Price increases in these cities do not seem to be driven by proportional increases in rents, but by the expectations of future price increases. This can be regarded as a sign of strong speculation in these regional markets, when the prices drift apart from the levels that are supported by the fundamental factors. However, in order to be able to talk about ensuing speculative bubbles in certain German cities, one needs to examine in more detail the trends of the real-estate market.

\section{Conclusion}

In this paper, we made two contributions. First, we computed the Internet-based quality-adjusted flat price and rent indices for 25 German cities over the period 2007:1-2012:9. Second, we conducted quasi out-of-sample 
forecasts of 1- through 12-month year-on-year growth rates of these indices over the period 2010:2-2012:9 using several dynamic panel data models with and without spatial effects.

Our main finding is that fixed-effects panel models accounting for spatial dependence produce the best forecast accuracy — as measured by the Root Mean Squared Forecast Error - compared to any other model examined in this paper. This finding remains robust across all forecasting horizons. Compared to the individual autoregressive models, these models lead to a decrease in the RMSFE by 5-7\% for both flats for sale and for rent.

In addition, a true out-of-sample exercise was undertaken to predict the growth rates of prices and rents for flats within the nearest 12 months, i.e., 2012:10-2013:10. It shows that in less than a half of all cities the flats' prices are expected to increase at a fairly strong rate. In contrast, the rents are expected to increase in the vast majority of the cities. However, in several cities the prices are projected to grow much faster than the rents, which might be explained by speculative tendencies. In the case of Berlin, a catching-up process might also be at work, which means that the current prices for flats are undervalued but are gradually adjusting to their fundamental value.

\section{References}

Aiolfi, M. and A. Timmermann (2006). Persistence in forecasting performance and conditional combination strategies. Journal of Econometrics 135(1-2), 31-53.

an de Meulen, P., M. Micheli, and T. Schmidt (2011). Forecasting house prices in Germany. Ruhr Economic Papers 0294, Rheinisch-Westflisches Institut für Wirtschaftsforschung, Ruhr-Universität Bochum, Universität Dortmund, Universität Duisburg-Essen.

Arellano, M. and S. Bond (1991). Some tests of specification for panel data: Monte Carlo evidence and an application to employment equations. Review of Economic Studies 58(2), 277-297.

Baltagi, B. H. and J. M. Griffin (1997). Pooled estimators vs. their heterogeneous counterparts in the context of dynamic demand for gasoline. Journal of Econometrics r7(2), 303-327. 
Baltagi, B. H. and D. Li (2006). Prediction in the panel data model with spatial correlation. Spatial Economic Analysis 1, 175-185.

Brücker, H. and B. Siliverstovs (2006). On the estimation and forecasting of international migration: How relevant is heterogeneity across countries? Empirical Economics 31(3), 735-754.

Doornik, J. A., M. Arellano, and S. Bond (2006). Panel data estimation using DPD for Ox. Mimeo.

Doornik, J. A. and M. Ooms (2006). Introduction to Ox. London: Timberlake Consultants Press.

Elhorst, J. P. (2005). Unconditional maximum likelihood estimation of linear and log-linear dynamic models for spatial panels. Geographical Analysis 37, 85-106.

Girardin, E. and K. A. Kholodilin (2011). How helpful are spatial effects in forecasting the growth of Chinese provinces? Journal of Forecasting 30, 622-643.

Kholodilin, K. A. and A. Mense (2012). Internet-based hedonic indices of rents and prices for flats. Example of Berlin. DIW Berlin Discussion Paper 1191.

Kholodilin, K. A., B. Siliverstovs, and S. Kooths (2008). A dynamic panel data approach to the forecasting of the GDP of German Länder. Spatial Economic Analysis 3(2), 195-207.

Longhi, S. and P. Nijkamp (2007). Forecasting regional labor market developments under spatial heterogeneity and spatial correlation. International Regional Science Review 30, 100-119.

Ramanathan, R. (1995). Introductory Econometrics. Dryden Press/Harcourt Brace. 


\section{Appendix}

Table 1: Structural characteristics of a typical flat

\begin{tabular}{l|cc|cc}
\hline \multirow{2}{*}{ City } & \multicolumn{3}{|c|}{ Flats for sale } & \multicolumn{2}{c}{ Flats for rent } \\
\cline { 2 - 5 } & $\begin{array}{c}\text { Number } \\
\text { of rooms }\end{array}$ & Area & $\begin{array}{c}\text { Number } \\
\text { of rooms }\end{array}$ & Area \\
\hline Augsburg & 3 & 72.0 & 2 & 62.0 \\
Berlin & 3 & 81.9 & 2 & 67.5 \\
Bielefeld & 3 & 77.0 & 3 & 68.0 \\
Bochum & 3 & 78.0 & 3 & 64.0 \\
Bonn & 3 & 76.0 & 2.5 & 72.0 \\
Bremen & 3 & 70.0 & 3 & 63.1 \\
Dortmund & 3 & 75.0 & 3 & 64.6 \\
Dresden & 3 & 75.6 & 2 & 62.7 \\
Düsseldorf & 3 & 78.0 & 2 & 67.0 \\
Duisburg & 3 & 70.0 & 3 & 64.8 \\
Essen & 3 & 75.0 & 3 & 64.0 \\
FrankfurtM & 3 & 83.0 & 2.5 & 71.0 \\
Gelsenkirchen & 3 & 70.0 & 3 & 62.0 \\
Hamburg & 3 & 78.0 & 2.5 & 66.0 \\
Hannover & 3 & 73.0 & 3 & 66.5 \\
Köln & 3 & 76.2 & 2 & 66.0 \\
Krefeld & 3 & 74.0 & 3 & 69.0 \\
Leipzig & 3 & 70.6 & 2 & 64.0 \\
Mannheim & 3 & 73.4 & 2 & 65.0 \\
Mönchengladbach & 3 & 76.0 & 3 & 70.7 \\
München & 3 & 75.0 & 2 & 66.2 \\
Nürnberg & 3 & 75.0 & 2 & 63.0 \\
Stuttgart & 3 & 76.5 & 3 & 69.5 \\
Wiesbaden & 3 & 84.0 & 3 & 71.0 \\
Wuppertal & 3 & 76.4 & 2 & 66.0 \\
\hline
\end{tabular}




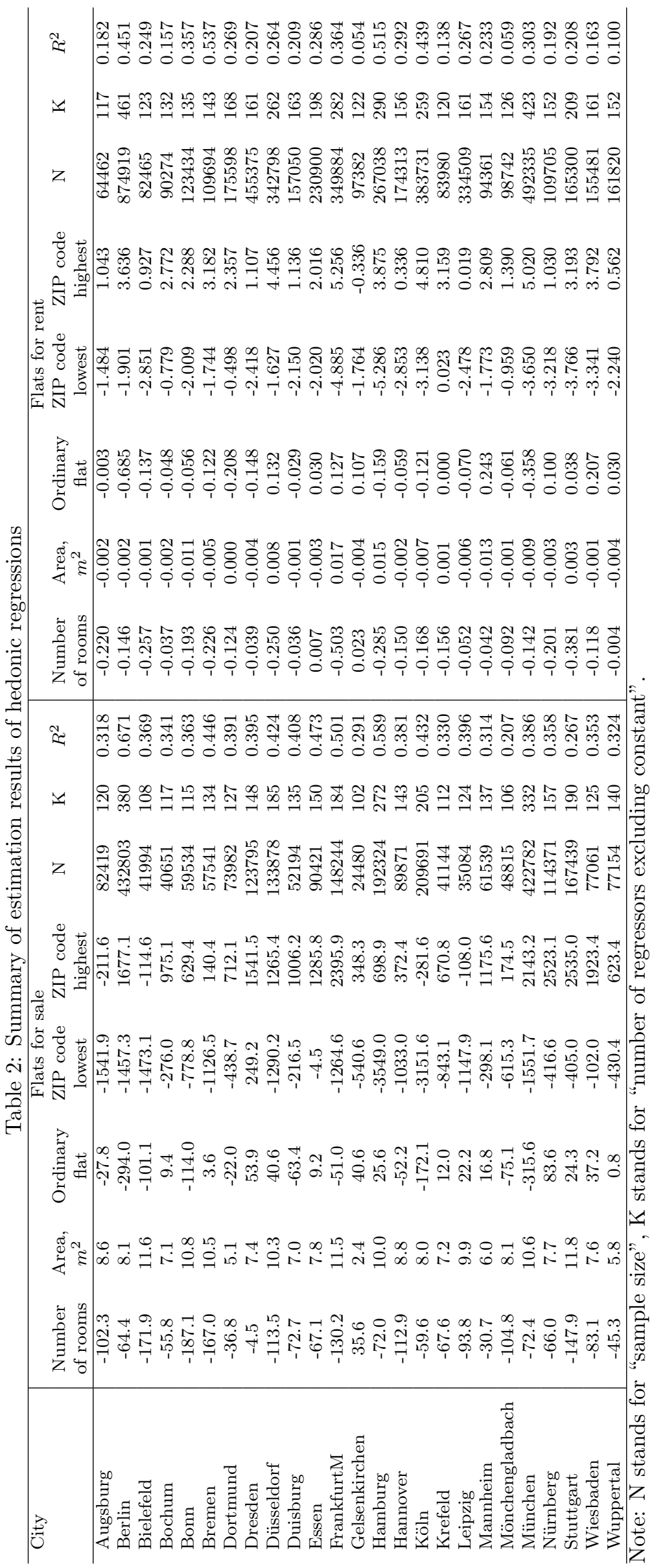




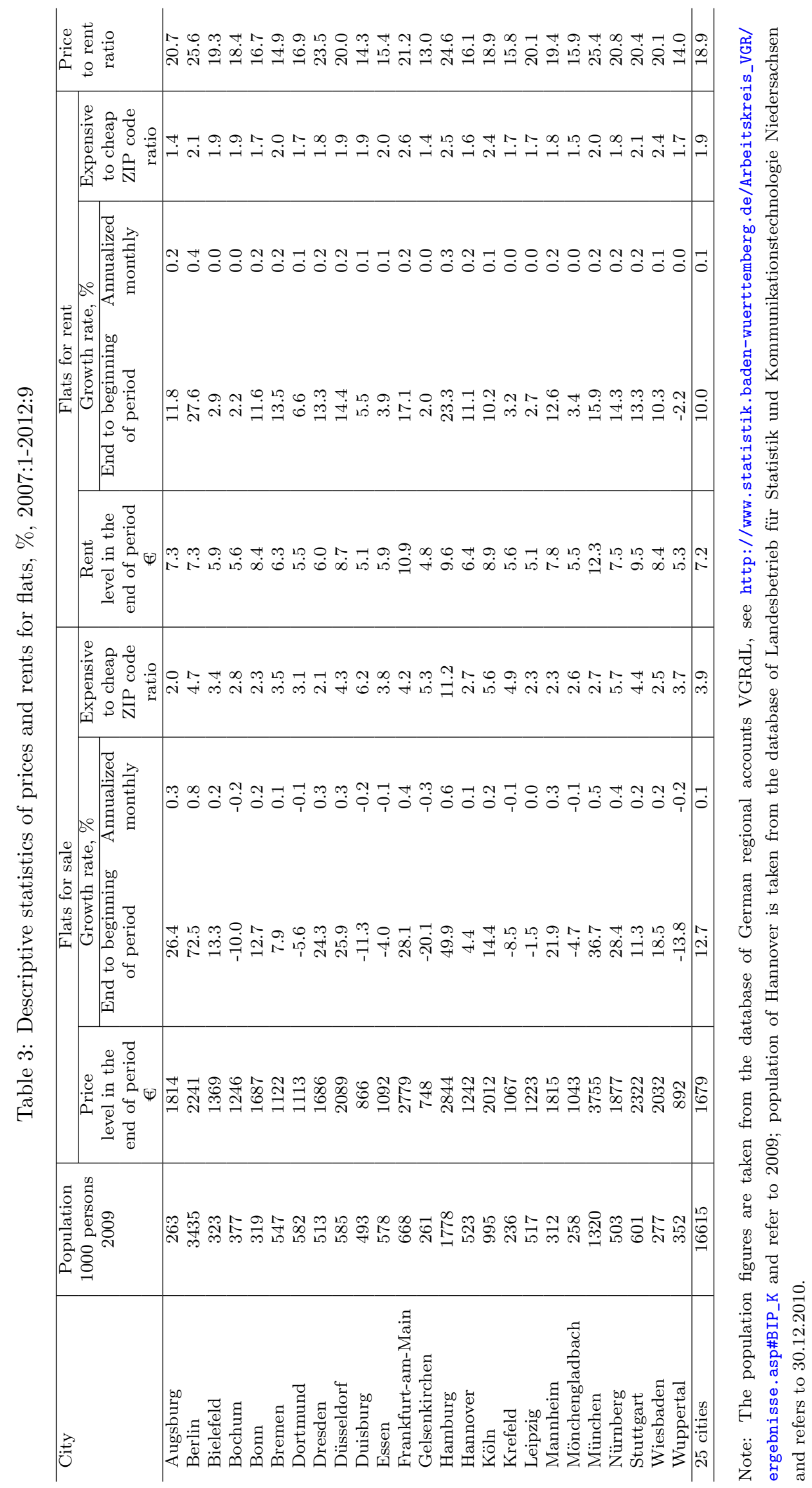


Table 4: Estimation results of the flats' price models, 2008:2-2012:9

\begin{tabular}{|c|c|c|c|c|c|c|c|c|}
\hline & \multicolumn{4}{|c|}{ No spatial effects } & \multicolumn{4}{|c|}{ Spatial effects } \\
\hline & \multicolumn{2}{|c|}{$I_{O L S}$} & \multirow{2}{*}{$\begin{array}{c}P_{O L S} \\
(3)\end{array}$} & \multirow{2}{*}{$\begin{array}{c}F E_{O L S} \\
(4)\end{array}$} & \multirow{2}{*}{$\begin{array}{c}P_{M L E}^{S L M} \\
(5)\end{array}$} & \multirow{2}{*}{$\begin{array}{c}F E_{M L E}^{S L M} \\
(6)\end{array}$} & \multirow{2}{*}{$\begin{array}{c}P_{M L E}^{S E M} \\
(7)\end{array}$} & \multirow{2}{*}{$\begin{array}{c}F E_{M L E}^{S E M} \\
(8)\end{array}$} \\
\hline & $\begin{array}{l}\text { Minimum } \\
\text { (1) }\end{array}$ & $\begin{array}{c}\text { Maximum } \\
\text { (2) }\end{array}$ & & & & & & \\
\hline$\alpha$ & -0.487 & $0.728^{* *}$ & $0.252^{* * *}$ & & $0.180^{* * *}$ & & $0.281^{* * *}$ & \\
\hline$\beta$ & $0.512^{* * *}$ & $0.996^{* * *}$ & $0.918^{* * *}$ & $0.822^{* * *}$ & $0.864^{* * *}$ & $0.770 * * *$ & $0.907^{* * *}$ & $0.832^{* * *}$ \\
\hline$\lambda$ & - & - & - & - & - & - & 0.138 & 0.182 \\
\hline$\rho$ & - & - & - & - & $0.147^{* * *}$ & $0.217^{* * *}$ & - & - \\
\hline$R^{2}$ & 0.259 & 0.934 & 0.820 & 0.637 & 0.827 & 0.834 & 0.822 & 0.719 \\
\hline
\end{tabular}

Table 5: Estimation results of the flats' rent models, 2008:2-2012:9

\begin{tabular}{|c|c|c|c|c|c|c|c|c|}
\hline & \multicolumn{4}{|c|}{ No spatial effects } & \multicolumn{4}{|c|}{ Spatial effects } \\
\hline & \multicolumn{2}{|c|}{$I_{O L S}$} & \multirow{2}{*}{$\begin{array}{c}P_{O L S} \\
(3)\end{array}$} & \multirow{2}{*}{$\begin{array}{c}F E_{O L S} \\
(4)\end{array}$} & \multirow{2}{*}{$\begin{array}{c}P_{M L E}^{S L M} \\
(5)\end{array}$} & \multirow{2}{*}{$\begin{array}{c}F E_{M L E}^{S L M} \\
(6)\end{array}$} & \multirow{2}{*}{$\begin{array}{c}P_{M L E}^{S E M} \\
(7)\end{array}$} & \multirow{2}{*}{$\begin{array}{c}F E_{M L E}^{S E M} \\
(8)\end{array}$} \\
\hline & (1) & $\begin{array}{l}\operatorname{Maximum} \\
(2)\end{array}$ & & & & & & \\
\hline$\alpha$ & -0.010 & $1.272^{* *}$ & $0.262^{* * *}$ & & $0.119^{* * *}$ & & $0.275^{* * *}$ & \\
\hline$\beta$ & $0.595^{* * *}$ & $0.959^{* * *}$ & $0.856^{* * *}$ & $0.759^{* * *}$ & $0.822^{* * *}$ & $0.713^{* * *}$ & $0.850^{* * *}$ & $0.743^{* * *}$ \\
\hline$\lambda$ & - & - & - & - & - & - & 0.078 & $0.130^{* * *}$ \\
\hline$\rho$ & - & - & - & - & $0.141^{* * *}$ & $0.190^{* * *}$ & - & - \\
\hline$R^{2}$ & 0.370 & 0.926 & 0.737 & 0.579 & 0.743 & 0.756 & 0.738 & 0.582 \\
\hline
\end{tabular}


Table 6: Quasi out-of-sample forecast accuracy of flats' price models (RMSFE), 2010:1-2012:9

\begin{tabular}{|c|c|c|c|c|c|c|c|c|c|}
\hline \multirow[t]{4}{*}{ Horizon } & \multicolumn{5}{|c|}{ No spatial effects } & \multicolumn{4}{|c|}{ Spatial effects } \\
\hline & \multicolumn{3}{|c|}{ Individual } & \multicolumn{2}{|c|}{ OLS } & \multicolumn{2}{|r|}{ SLM } & \multicolumn{2}{|c|}{ SEM } \\
\hline & Past value & Average & $\mathrm{AR}$ & Pooled & Fixed-effects & Pooled & Fixed-effects & Pooled & Fixed-effects \\
\hline & & & $I_{O L S}$ & $P_{O L S}$ & $F E_{O L S}$ & $P_{M L E}^{S L M}$ & $F E_{M L E}^{S L M}$ & $P_{M L E}^{S E M}$ & $F E_{M L E}^{S E M}$ \\
\hline 1 & 2.3 & 4.6 & 2.3 & 2.3 & 2.3 & 2.2 & 2.2 & 2.3 & 2.3 \\
\hline 2 & 4.8 & 9.1 & 4.7 & 4.8 & 4.9 & 4.6 & 4.6 & 4.8 & 4.9 \\
\hline 3 & 7.6 & 13.4 & 7.5 & 7.6 & 7.8 & 7.2 & 7.1 & 7.7 & 7.9 \\
\hline 4 & 10.5 & 17.7 & 10.4 & 10.7 & 10.9 & 9.9 & 9.8 & 10.8 & 11.2 \\
\hline 5 & 13.7 & 21.9 & 13.6 & 14.2 & 14.4 & 12.9 & 12.8 & 14.4 & 14.8 \\
\hline 6 & 17.0 & 26.1 & 17.1 & 17.8 & 18.0 & 16.0 & 15.9 & 18.0 & 18.5 \\
\hline 7 & 20.5 & 30.4 & 20.9 & 21.8 & 21.9 & 19.4 & 19.3 & 22.0 & 22.4 \\
\hline 8 & 24.1 & 34.6 & 25.0 & 26.0 & 26.0 & 23.0 & 22.8 & 26.2 & 26.5 \\
\hline 9 & 27.7 & 38.8 & 29.0 & 30.1 & 30.0 & 26.6 & 26.5 & 30.4 & 30.6 \\
\hline 10 & 31.6 & 43.0 & 33.2 & 34.6 & 34.2 & 30.6 & 30.4 & 34.9 & 35.0 \\
\hline 11 & 36.0 & 47.2 & 37.6 & 39.3 & 38.5 & 34.6 & 34.3 & 39.6 & 39.3 \\
\hline \multirow[t]{2}{*}{12} & 40.6 & 51.4 & 41.9 & 44.1 & 42.9 & 38.7 & 38.4 & 44.4 & 43.8 \\
\hline & \multicolumn{9}{|c|}{ Relative RMSFE $=R M S F E_{i} / R M S F E_{P V}$} \\
\hline 1 & 1.00 & 2.02 & 0.99 & 0.99 & 1.00 & 0.97 & 0.97 & 0.99 & 1.01 \\
\hline 2 & 1.00 & 1.88 & 0.98 & 0.99 & 1.01 & 0.96 & 0.95 & 1.00 & 1.02 \\
\hline 3 & 1.00 & 1.76 & 0.98 & 1.00 & 1.02 & 0.94 & 0.93 & 1.01 & 1.04 \\
\hline 4 & 1.00 & 1.68 & 0.99 & 1.02 & 1.04 & 0.94 & 0.93 & 1.03 & 1.06 \\
\hline 5 & 1.00 & 1.60 & 0.99 & 1.04 & 1.05 & 0.94 & 0.93 & 1.05 & 1.08 \\
\hline 6 & 1.00 & 1.54 & 1.01 & 1.05 & 1.06 & 0.94 & 0.94 & 1.06 & 1.09 \\
\hline 7 & 1.00 & 1.48 & 1.02 & 1.06 & 1.07 & 0.95 & 0.94 & 1.08 & 1.10 \\
\hline 8 & 1.00 & 1.43 & 1.03 & 1.08 & 1.08 & 0.96 & 0.95 & 1.09 & 1.10 \\
\hline 9 & 1.00 & 1.40 & 1.05 & 1.09 & 1.08 & 0.96 & 0.95 & 1.10 & 1.11 \\
\hline 10 & 1.00 & 1.36 & 1.05 & 1.10 & 1.08 & 0.97 & 0.96 & 1.10 & 1.11 \\
\hline 11 & 1.00 & 1.31 & 1.04 & 1.09 & 1.07 & 0.96 & 0.95 & 1.10 & 1.09 \\
\hline 12 & 1.00 & 1.27 & 1.03 & 1.09 & 1.06 & 0.95 & 0.95 & 1.09 & 1.08 \\
\hline
\end{tabular}

Table 7: Quasi out-of-sample forecast accuracy of flats' rent models (RMSFE), 2010:1-2012:9

\begin{tabular}{|c|c|c|c|c|c|c|c|c|c|}
\hline \multirow[t]{3}{*}{ Horizon } & \multicolumn{5}{|c|}{ No spatial effects } & \multicolumn{4}{|c|}{ Spatial effects } \\
\hline & \multicolumn{3}{|c|}{ Individual } & \multicolumn{2}{|r|}{ OLS } & \multicolumn{2}{|r|}{ SLM } & \multicolumn{2}{|c|}{ SEM } \\
\hline & Past value & Average & $\begin{array}{c}\mathrm{AR} \\
I_{O L S}\end{array}$ & $\begin{array}{c}\text { Pooled } \\
P_{O L S}\end{array}$ & $\begin{array}{c}\text { Fixed-effects } \\
F E_{O L S}\end{array}$ & $\begin{array}{l}\text { Pooled } \\
P_{M L M}^{S L M} \\
\end{array}$ & $\begin{array}{c}\text { Fixed-effects } \\
F E_{M L E}^{S L M}\end{array}$ & $\begin{array}{l}\text { Pooled } \\
P_{M E M}^{S E M} \\
\end{array}$ & $\begin{array}{c}\text { Fixed-effects } \\
F E_{M E M}^{S E M} \\
\end{array}$ \\
\hline 1 & 0.7 & 1.3 & 0.7 & 0.7 & 0.7 & 0.7 & 0.7 & 0.7 & 0.7 \\
\hline 2 & 1.5 & 2.5 & 1.5 & 1.5 & 1.5 & 1.5 & 1.5 & 1.5 & 1.6 \\
\hline 3 & 2.4 & 3.8 & 2.4 & 2.5 & 2.5 & 2.4 & 2.4 & 2.5 & 2.5 \\
\hline 4 & 3.3 & 5.0 & 3.5 & 3.6 & 3.5 & 3.4 & 3.4 & 3.6 & 3.6 \\
\hline 5 & 4.4 & 6.1 & 4.5 & 4.8 & 4.6 & 4.5 & 4.4 & 4.8 & 4.7 \\
\hline 6 & 5.5 & 7.3 & 5.7 & 6.0 & 5.7 & 5.7 & 5.5 & 6.1 & 5.8 \\
\hline 7 & 6.6 & 8.5 & 6.9 & 7.4 & 6.9 & 6.9 & 6.7 & 7.4 & 7.1 \\
\hline 8 & 7.9 & 9.7 & 8.2 & 8.8 & 8.1 & 8.2 & 7.9 & 8.8 & 8.3 \\
\hline 9 & 9.2 & 10.9 & 9.4 & 10.3 & 9.3 & 9.5 & 9.1 & 10.3 & 9.5 \\
\hline 10 & 10.6 & 12.1 & 10.8 & 11.8 & 10.5 & 10.9 & 10.4 & 11.8 & 10.8 \\
\hline 11 & 12.1 & 13.3 & 12.1 & 13.3 & 11.8 & 12.3 & 11.7 & 13.3 & 12.1 \\
\hline 12 & 13.7 & 14.5 & 13.6 & 14.9 & 13.1 & 13.8 & 13.1 & 14.9 & 13.4 \\
\hline \multicolumn{10}{|c|}{ Relative RMSFE $=R M S F E_{i} / R M S F E_{P V}$} \\
\hline 1 & 1.00 & 1.93 & 1.03 & 1.03 & 1.04 & 1.01 & 1.01 & 1.03 & 1.05 \\
\hline 2 & 1.00 & 1.71 & 1.03 & 1.04 & 1.04 & 1.01 & 1.01 & 1.04 & 1.05 \\
\hline 3 & 1.00 & 1.60 & 1.04 & 1.07 & 1.06 & 1.02 & 1.02 & 1.07 & 1.07 \\
\hline 4 & 1.00 & 1.49 & 1.04 & 1.09 & 1.06 & 1.03 & 1.02 & 1.09 & 1.08 \\
\hline 5 & 1.00 & 1.41 & 1.04 & 1.10 & 1.05 & 1.03 & 1.02 & 1.10 & 1.08 \\
\hline 6 & 1.00 & 1.35 & 1.04 & 1.11 & 1.05 & 1.04 & 1.01 & 1.11 & 1.07 \\
\hline 7 & 1.00 & 1.29 & 1.04 & 1.12 & 1.04 & 1.04 & 1.01 & 1.12 & 1.06 \\
\hline 8 & 1.00 & 1.23 & 1.04 & 1.12 & 1.03 & 1.04 & 1.00 & 1.12 & 1.05 \\
\hline 9 & 1.00 & 1.18 & 1.02 & 1.11 & 1.01 & 1.03 & 0.99 & 1.12 & 1.03 \\
\hline 10 & 1.00 & 1.15 & 1.02 & 1.11 & 1.00 & 1.03 & 0.99 & 1.12 & 1.02 \\
\hline 11 & 1.00 & 1.10 & 1.01 & 1.10 & 0.98 & 1.02 & 0.97 & 1.10 & 1.00 \\
\hline 12 & 1.00 & 1.05 & 0.99 & 1.08 & 0.95 & 1.00 & 0.95 & 1.09 & 0.98 \\
\hline
\end{tabular}


Table 8: Predicted average year-on-year growth rates of prices and rents for flats, \%, 2012:10-2013:10

\begin{tabular}{|c|c|c|c|c|}
\hline \multirow[t]{2}{*}{ City } & \multicolumn{2}{|c|}{ Flats for sale } & \multicolumn{2}{|r|}{ Flats for rent } \\
\hline & $\begin{array}{l}\text { Past } \\
\text { value }\end{array}$ & $\begin{array}{c}\text { Fixed-effects } \\
\text { SLM }\end{array}$ & $\begin{array}{l}\text { Past } \\
\text { value }\end{array}$ & $\begin{array}{c}\text { Fixed-effects } \\
\text { SLM }\end{array}$ \\
\hline & (1) & (2) & $(3)$ & (4) \\
\hline Augsburg & 16.5 & 12.2 & 3.6 & 2.7 \\
\hline Berlin & 17.7 & 14.5 & 6.3 & 5.2 \\
\hline Bielefeld & 2.0 & 4.2 & 2.9 & 1.9 \\
\hline Bochum & 0.1 & -0.4 & 1.2 & 1.1 \\
\hline Bonn & 5.4 & 5.0 & 5.1 & 3.1 \\
\hline Bremen & 2.1 & 3.5 & 4.0 & 3.2 \\
\hline Dortmund & -1.8 & -0.2 & 2.3 & 1.6 \\
\hline Dresden & 11.3 & 9.6 & 3.3 & 2.8 \\
\hline Düsseldorf & 12.3 & 8.1 & 3.9 & 3.0 \\
\hline Duisburg & -2.0 & -1.1 & 0.8 & 1.1 \\
\hline Essen & -0.5 & 0.0 & 2.4 & 1.3 \\
\hline FrankfurtM & 9.0 & 9.1 & 3.4 & 3.2 \\
\hline Gelsenkirchen & -5.9 & -3.3 & 1.0 & 0.9 \\
\hline Hamburg & 10.6 & 10.7 & 3.3 & 4.1 \\
\hline Hannover & 4.7 & 3.8 & 2.0 & 2.3 \\
\hline Köln & 3.6 & 4.7 & 3.7 & 2.6 \\
\hline Krefeld & 1.3 & 1.1 & 1.9 & 1.2 \\
\hline Leipzig & 6.6 & 5.1 & 1.4 & 1.2 \\
\hline Mannheim & 12.4 & 8.4 & 2.5 & 2.7 \\
\hline Mönchengladbach & -0.2 & 1.3 & 1.3 & 0.9 \\
\hline München & 9.8 & 12.5 & 3.9 & 3.1 \\
\hline Nürnberg & 15.8 & 11.3 & 4.1 & 3.2 \\
\hline Stuttgart & 7.6 & 7.5 & 4.3 & 2.9 \\
\hline Wiesbaden & 8.2 & 7.7 & 3.2 & 2.3 \\
\hline Wuppertal & 1.7 & -0.4 & -1.3 & 0.1 \\
\hline 25 cities & 5.9 & 5.4 & 2.8 & 2.3 \\
\hline
\end{tabular}




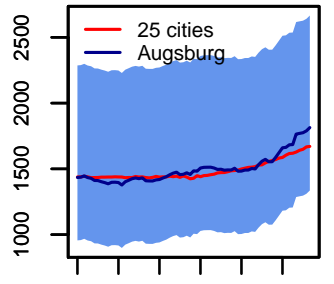

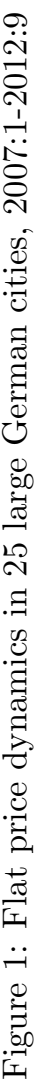
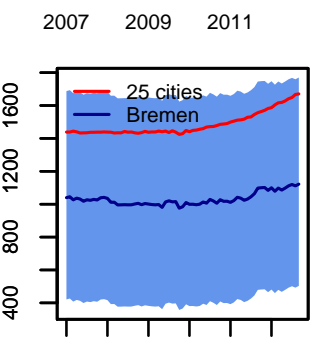

$20072009 \quad 2011$
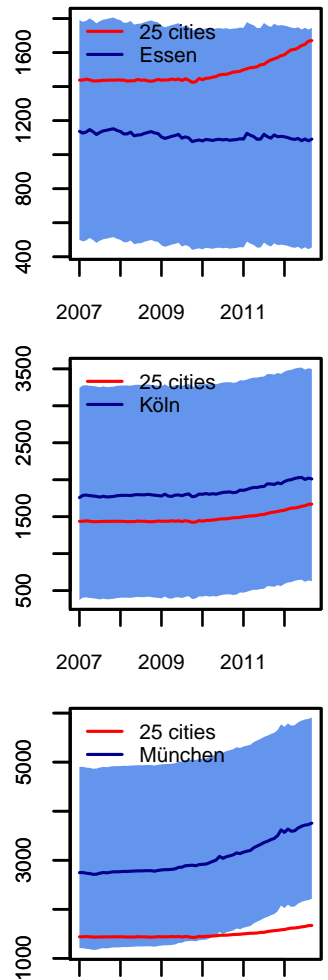

$2007 \quad 2009 \quad 2011$

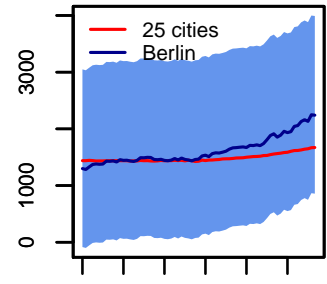

200720092011

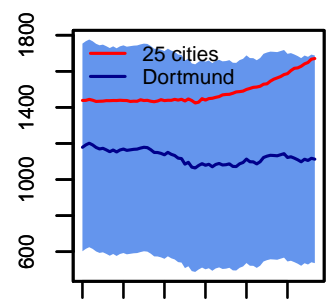

200720092011

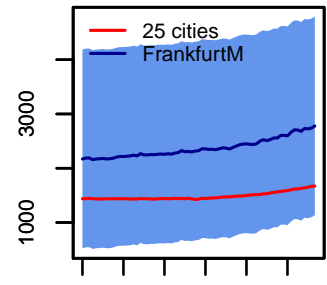

200720092011
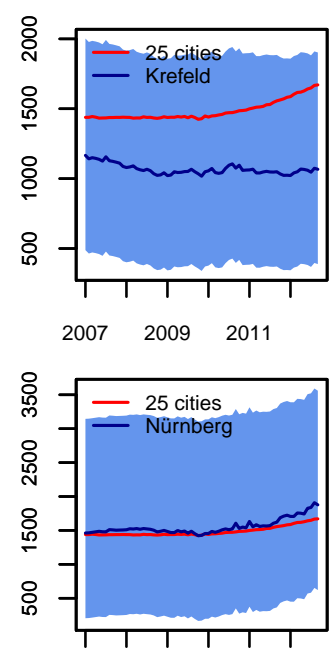

$2007 \quad 2009 \quad 2011$

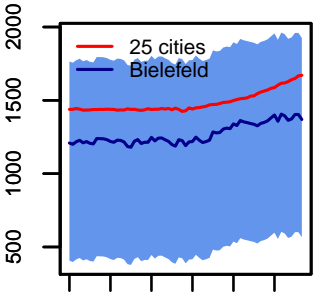

200720092011

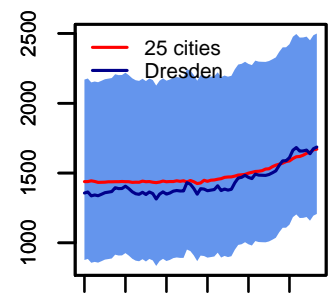

200720092011

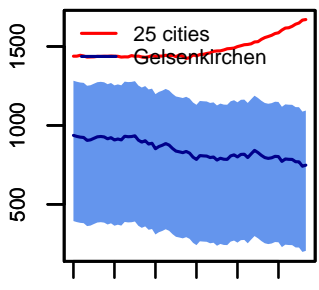

$20072009 \quad 2011$
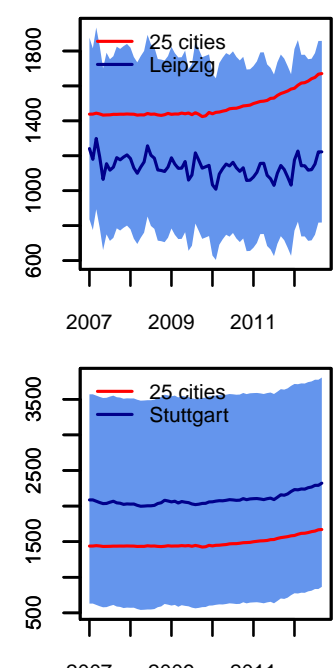

$2007 \quad 2009 \quad 2011$

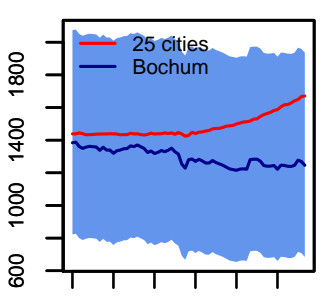

200720092011

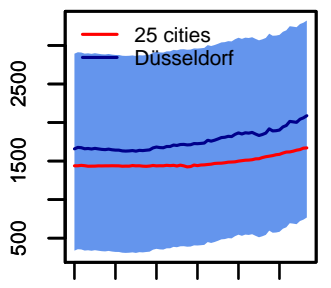

$20072009 \quad 2011$

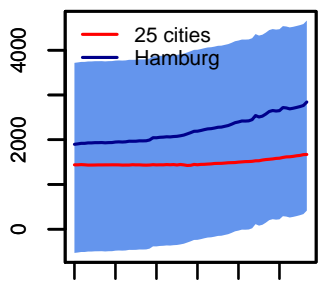

200720092011

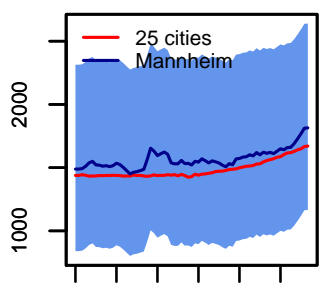

$2007 \quad 2009 \quad 2011$

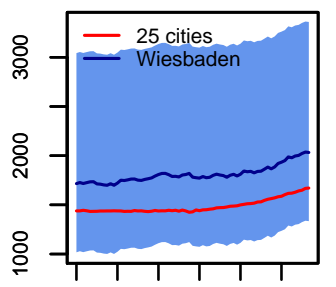

$2007 \quad 2009 \quad 2011$

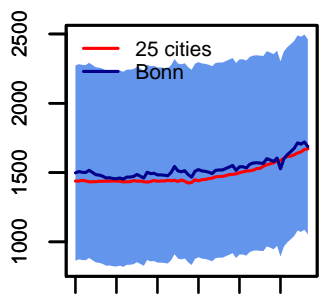

$2007 \quad 2009 \quad 2011$

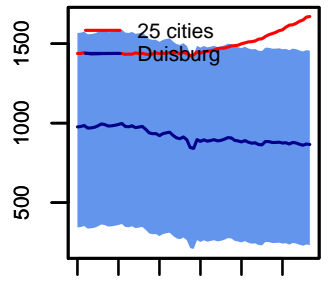

$2007 \quad 2009 \quad 2011$

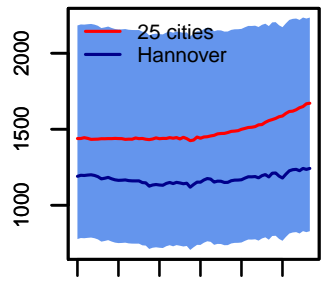

$20072009 \quad 2011$

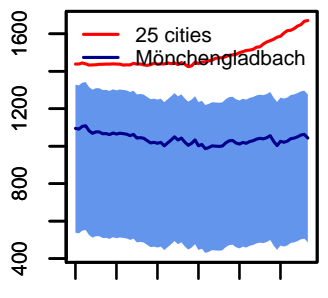

$2007 \quad 2009 \quad 2011$

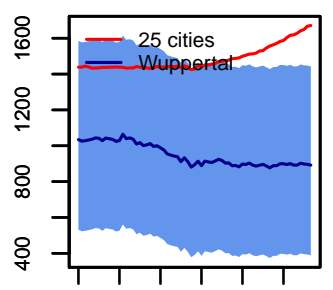

$2007 \quad 2009 \quad 2011$ 


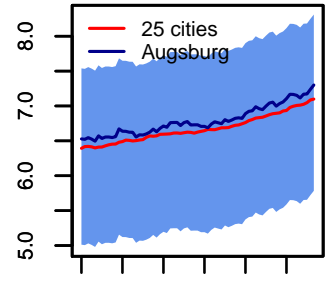

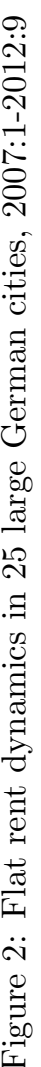

200720092011

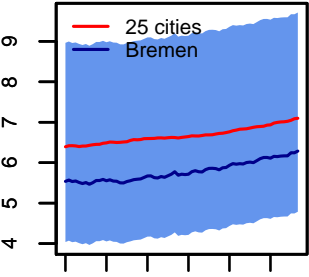

$20072009 \quad 2011$

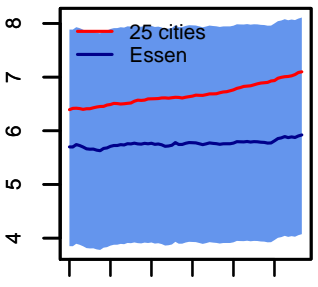

$20072009 \quad 2011$
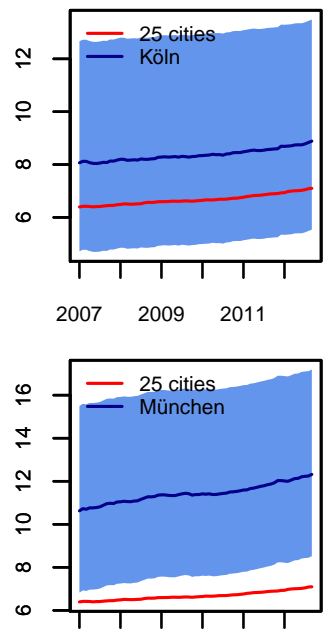

$2007 \quad 2009 \quad 2011$

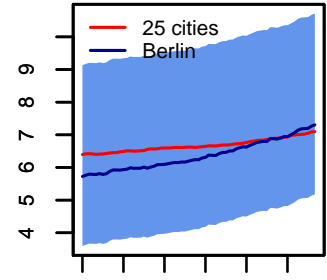

200720092011

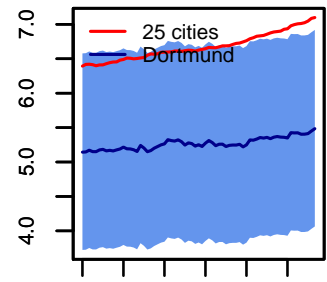

200720092011
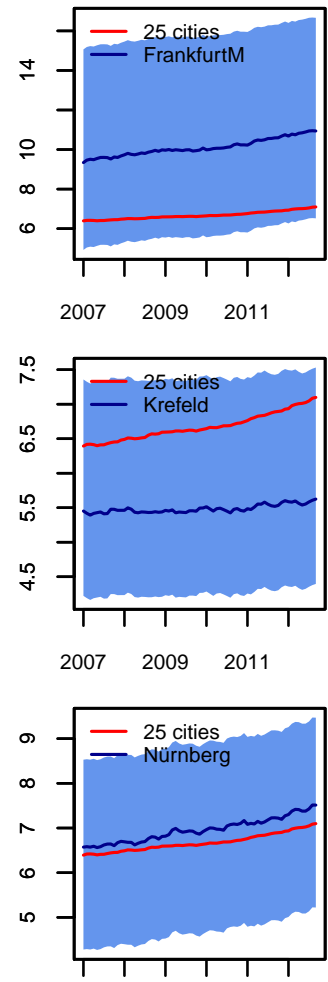

$2007 \quad 2009 \quad 2011$

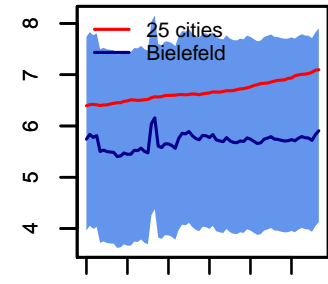

200720092011

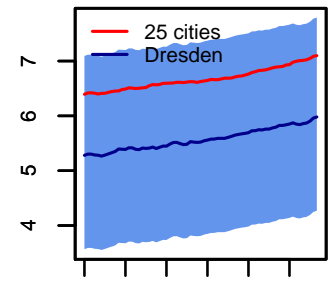

200720092011

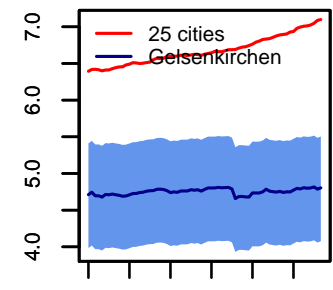

200720092011

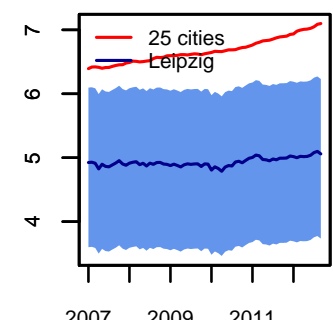

$2007 \quad 2009 \quad 2011$

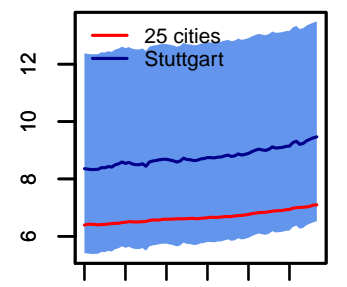

$2007 \quad 2009 \quad 2011$

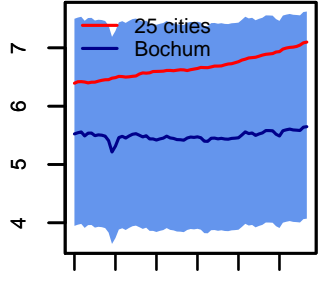

$2007 \quad 20092011$

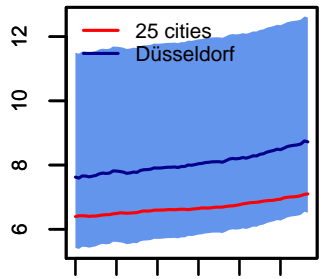

$20072009 \quad 2011$

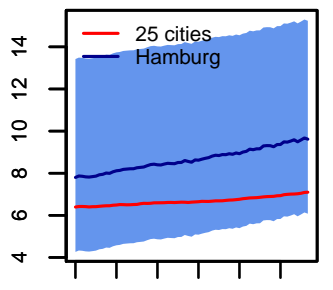

$20072009 \quad 2011$
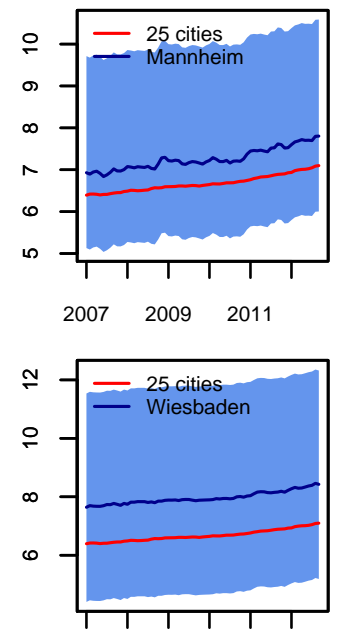

$2007 \quad 2009 \quad 2011$
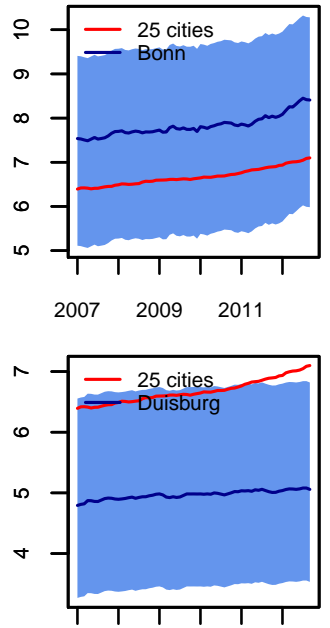

200720092011

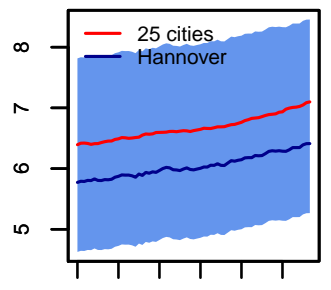

$2007 \quad 2009 \quad 2011$
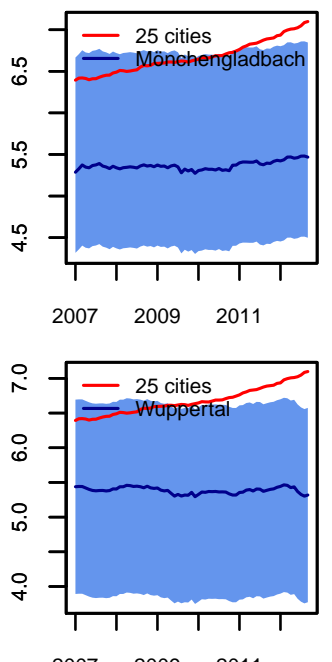

$2007 \quad 2009 \quad 2011$ 

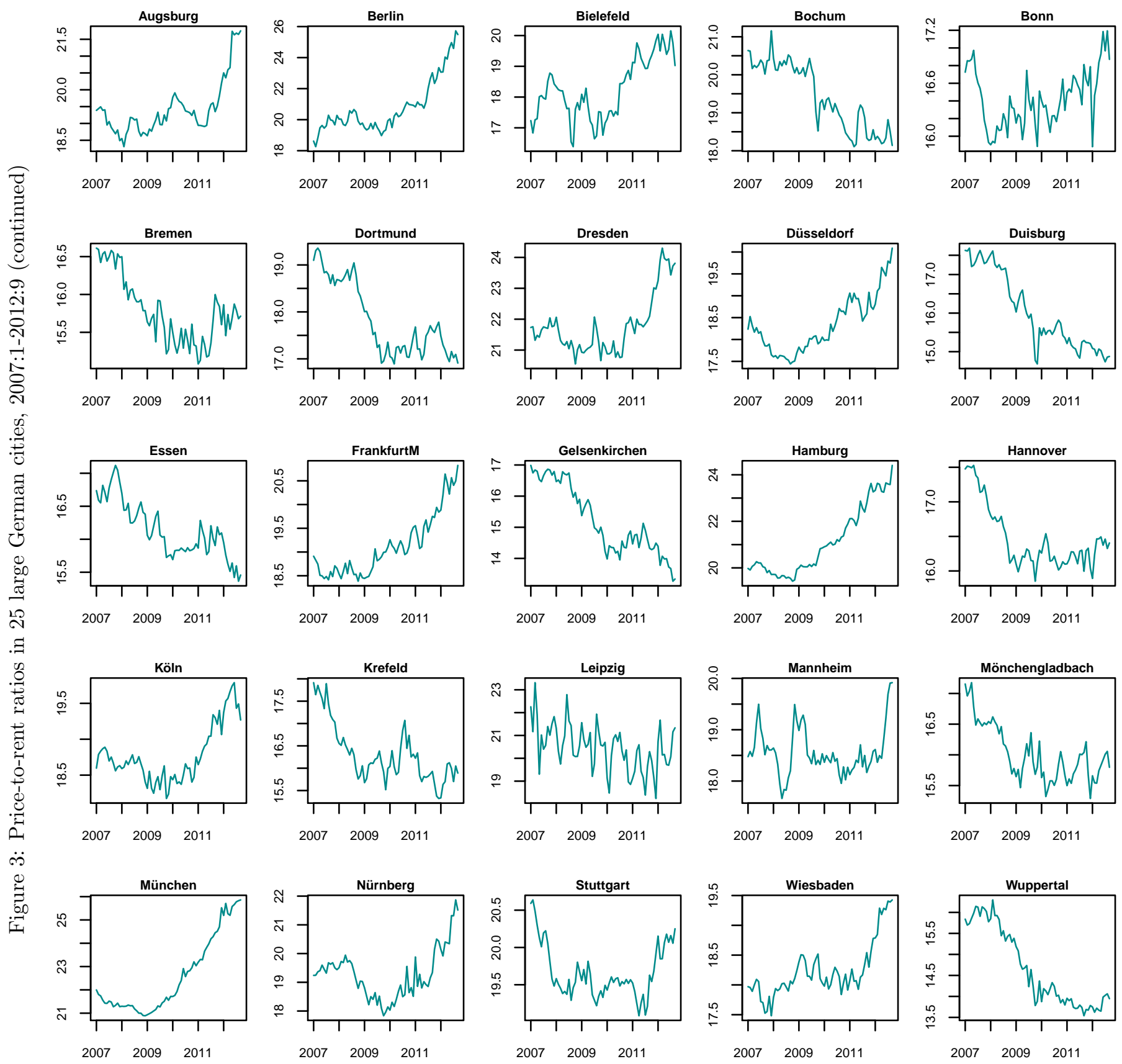

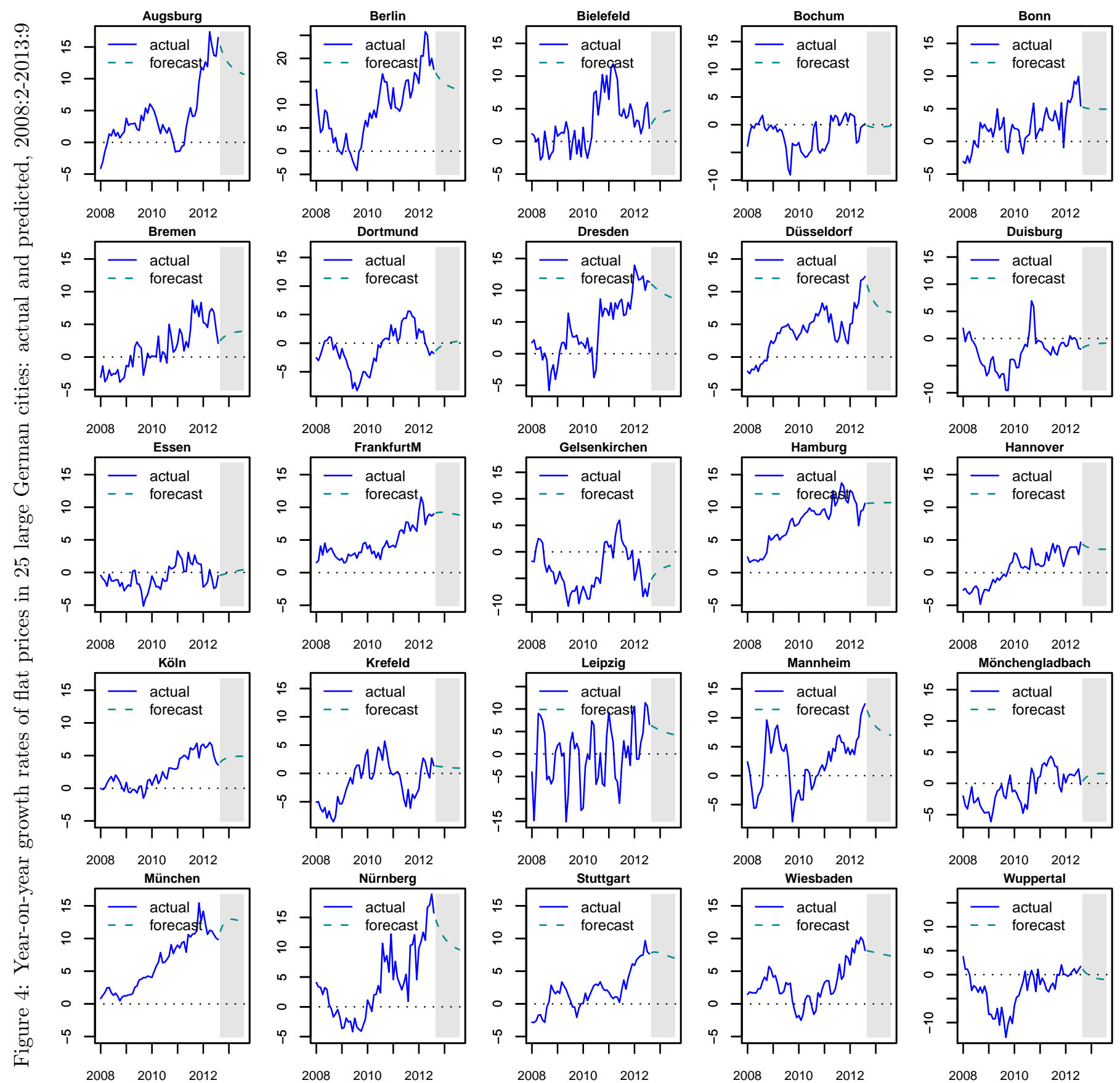

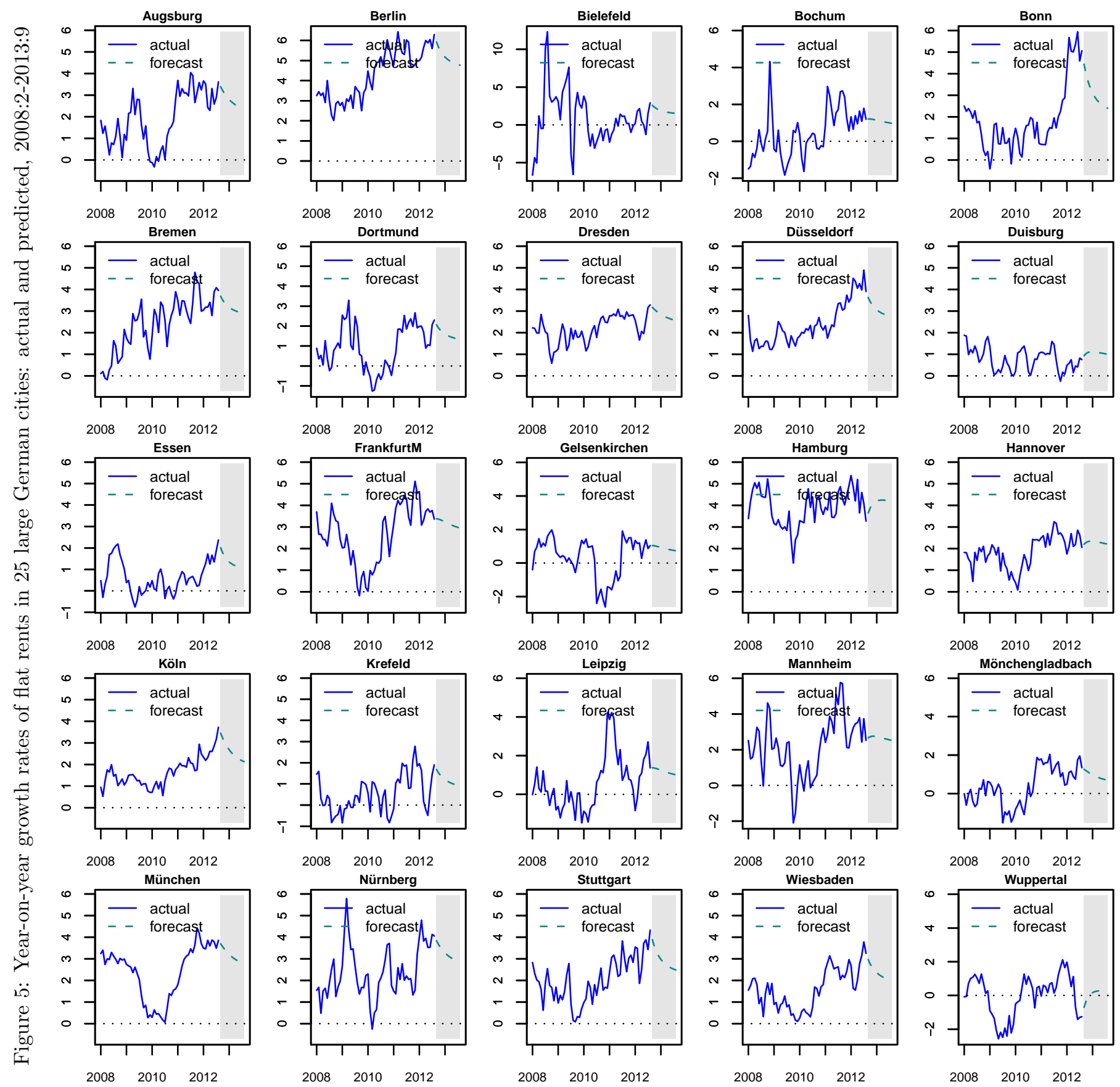